\title{
Editorial
}

\section{A Milestone to Consider: A Note from the Editor-in-Chief on the First Impact Factor for the International Journal of Tropical Insect Science (IJT)}

(First published online 7 September 2015)

On behalf of the IJT Board, I am thrilled to announce the first Impact Factor for the International Journal of Tropical Insect Science (IJT), which was recently published in Thomson Reuters' 2015 Journal Citation Reports ${ }^{\circledR}$ (JCR). The information was gathered from the 2014 citation data for items published in 2012 and 2013. According to the release, our first Impact Factor is 0.419 , an encouraging result and one we aspire to build on in the coming years. IJT also joins the 'Entomology' subject category in Science Citation Index (SCI) Expanded, where it is ranked 76th out of 92 journal titles.

Obtaining an Impact Factor was the longtime goal of my predecessor, Prof. Christian Borgemeister (now the Director of the Ecology and Natural Resources Management Department at the Centre for Development Research [ZEF] of the University of Bonn, Germany), who expressed great joy on learning about this milestone. He is pleased that this first Impact Factor, relating to papers published during his tenure, has been worth the wait.

First published in 1980, IJT is a long-standing and invaluable resource for the entomological research community. We are optimistic that the release of the Impact Factor will boost submissions to the Journal, allowing the title to fully benefit from the recent changes to the management of submissions. In acknowledgement of the increasing need for distillation of the scientific literature, we intend to publish a larger volume of review articles. We encourage authors to submit review articles relating to critical or rapidly developing areas of tropical insect science, and look forward to discussing these ideas with you.

The Journal has now moved to an online-only format (EISSN: 1742-7592), reflecting the evolving patterns of usage seen in recent years. In this revised format, IJT continues to be a vehicle for the publication of high quality, relevant, and timely original, peer-reviewed research findings on tropical insects and related arthropods, with special emphasis on their environmentally benign and sustainable management. The Journal's scope consists of papers in arthropod ecology and biodiversity, ethno-entomology, arthropod taxonomy, integrated pest and vector management, and environmental issues, among others. Papers and abstracts are published in English, and the Journal has no page or submission charges. Authors wishing to make their papers Open Access (freely available on publication) can do so for a one-time payment.

In addition to our regular issues, the Journal also publishes occasional special issues on topical themes. Our most recent special issue (Volume 35, Issue S1) addresses the development and improvement of rearing techniques for fruit flies of economic importance, and can be accessed at: www.journals.cambridge.org/action/display Issue $?$ decade $=2010 \& \mathrm{jid}=\mathrm{JTI} \&$ volumeId $=34 \&$ issueId $=$ S1\&iid $=9377479$

The acquisition of an Impact Factor is an important milestone for the Journal and one that marks an exciting new phase in the title's development. We look forward to working closely with the scientific community in continuing IJT's upward trajectory.

We hope that the research community will continue to support the Journal through this exciting new phase of its development, working with us to ensure that IJT continues to respond to its evolving needs.

Segenet Kelemu, Editor-in-Chief 